\title{
BMJ Open Factors and outcomes associated with ultra-early surgery for poor-grade aneurysmal subarachnoid haemorrhage: a multicentre retrospective analysis
}

To cite: Zhao B, Zhao Y, $\operatorname{Tan} \mathrm{X}$, et al. Factors and outcomes associated with ultra-early surgery for poorgrade aneurysmal subarachnoid haemorrhage: a multicentre retrospective analysis. BMJ Open 2015;5: e007410. doi:10.1136/ bmjopen-2014-007410

- Prepublication history for this paper is available online. To view these files please visit the journal online (http://dx.doi.org/10.1136/ bmjopen-2014-007410).

Received 9 December 2014 Revised 22 March 2015 Accepted 25 March 2015

CrossMark

For numbered affiliations see end of article.

Correspondence to

Dr Shuo Wang; captain9858@vip.sina.com and Dr Ming Zhong; zhongming158@sohu.com

\section{ABSTRACT}

Objective: To determine factors and outcomes associated with ultra-early surgery for poor-grade aneurysmal subarachnoid haemorrhage (aSAH).

Design: A multicentre retrospective analysis, observational study.

Setting: High-volume teaching hospitals (more than 150 aSAH cases per year).

Participants: 118 patients with World Federation of Neurosurgical Societies (WFNS) grades IV and V underwent surgical treatment. Ultra-early surgery was defined as surgery performed within $24 \mathrm{~h}$ of aSAH, and delayed surgery as surgery performed after $24 \mathrm{~h}$. Outcome was assessed by modified Rankin Scale (mRS). The mean time of follow-up was 12.5 \pm 3.4 months (range 6-28 months).

Results: 47 (40\%) patients underwent ultra-early surgery, and $71(60 \%)$ patients underwent delayed surgery. Patients with WFNS grade V $(p=0.011)$ and brain herniation $(p=0.004)$ more often underwent ultraearly surgery. Postoperative complications were similar in ultra-early and delayed surgery groups. Adjusted multivariate analysis showed the outcomes were similar between the two groups. Multivariate analysis of predictors of poor outcome, ultraearly surgery was not an independent predictor of poor outcome, while advanced age, postresuscitation WFNS V grade, intraventricular haemorrhage, brain herniation and nonmiddle cerebral artery (MCA) aneurysms were associated with poor outcome.

Conclusions: Although patients with WFNS grade V and brain herniation more often undergo ultra-early surgery, postoperative complications and outcomes in selected patients were similar in the two groups. Patients of younger age, WFNS grade IV, absence of intraventricular haemorrhage, absence of brain herniation and MCA aneurysms are more likely to have a good outcome. Ultra-early surgery could improve outcomes in carefully selected patients with poor-grade aSAH.

\section{INTRODUCTION}

Aneurysmal subarachnoid haemorrhage (aSAH) is a devastating condition with high

\section{Strengths and limitations of this study}

- This is a relatively large, contemporary cohort of poor-grade aneurysmal subarachnoid haemorrhage after surgical treatment.

- Patients with World Federation of Neurosurgical Societies grade $\mathrm{V}$ and brain herniation more often undergo ultra-early surgery. Postoperative complications and outcomes in selected patients were similar between groups.

- This study evaluated predictors of poor outcome based on contemporary multicentre cohorts.

- The timing of surgery is not randomised, and a retrospective analysis has selection bias.

morbidity and mortality. Aneurysm rebleeding and cerebral vasospasm are the most important causes of morbidity and mortality. ${ }^{12}$ Poor-grade aSAH has a higher risk of rebleeding and cerebral vasospasm than good-grade aSAH. ${ }^{3-6}$ In the past decades, several studies have shown that early surgery potentially improves outcomes in selected patients with poor-grade aSAH. ${ }^{6-14}$ However, this approach is still associated with a high mortality and morbidity. ${ }^{69121516}$

Recently, ultra-early treatment (within $24 \mathrm{~h}$ of ictus) has been reported to reduce the risk of rebleeding and improve outcomes in the majority of patients with good-grade aSAH. ${ }^{17-19}$ Treatment for aneurysm as early as possible is also recommended to prevent rebleeding after initial aSAH. ${ }^{20}{ }^{21}$ However, poor-grade patients often present with worse clinical condition and experience more severe brain swelling than good-grade patients. ${ }^{22}{ }^{23}$ In the recent decades, endovascular treatment has provided an available alternative to surgery of poor-grade aSAH. ${ }^{24-29}$ Current surgical indications may differ from previous studies. However, no study has evaluated factors associated with ultra-early and 
delayed surgery for poor-grade aSAH in the modern endovascular era.

In this study, we analysed data from contemporary multicentre cohorts of poor-grade aSAH, and we determined factors and outcomes associated with ultra-early surgery compared with delayed surgery.

\section{METHODS}

This is a multicentre retrospective analysis. All patients were treated in high-volume teaching hospitals (more than 150 aSAH cases per year) with expertise in aneurysm clipping and coiling. This study was approved by the Chinese Ethics Committee of Registering Clinical Trials and the Institutional Review Board of Beijing Tiantan Hospital, Capital Medical University.

\section{Patient population}

Between October 2010 and March 2012, 109 patients with poor-grade aSAH (World Federation of Neurosurgical Societies (WFNS) grades IV and V) after hospitalisation, who underwent surgical treatment, were included in A Multicenter prospective Poor-grade Aneurysmal Subarachnoid haemorrhage registry Study (AMPAS). ${ }^{30}$ Between March 2012 and April 2014, 289 patients with aSAH undergoing surgery were included in the database of the China National Clinical Research Center for Neurological Diseases (NCRC-ND), and 35 (12\%) consecutive poor-grade patients were identified. Patients were excluded in current databases if they die after resuscitation, or the family withdrew care in the emergency room. In this study, poor-grade patients were included if they were older than 18 years and less than 75 years, presented with WFNS grade IV or V, did not improve after resuscitation, and underwent surgical treatment. Patients were excluded if they experienced neurological deterioration (WFNS grades I-III to IV-V) after hospitalisation, if they underwent aneurysm coiling, if they underwent surgery more than 21 days after aSAH, and if their last follow-up was less than 6 months.

\section{Clinical management}

Management protocol included aggressive resuscitation, intensive critical care, early CT angiography or cerebral angiography if possible, early surgery if possible and postoperative intensive care. ${ }^{30}$ All patients with poorgrade aSAH were resuscitated in the emergency room. After resuscitation, they were assessed by a multidisciplinary team which consisted of vascular neurosurgeons, interventional neuroradiologists and anaesthetists. Treatment options were discussed with the patient's family or relatives. Surgical selection was based on aneurysm morphology, patient's neurological condition, and treatment-relative risk following multidisciplinary consultation. After surgery, patients were transferred to the intensive care unit, and they underwent standard management for vasospasm.

\section{Data collection}

Ultra-early surgery was defined as surgery within $24 \mathrm{~h}$ of ictus, and delayed surgery as surgery after $24 \mathrm{~h}$. The time of ictus was defined as the time of loss of consciousness (poor-grade clinical condition). We reviewed the following data: age, sex, history of smoking, medical history, WFNS grade after resuscitation, brain herniation, Fisher grade, intracerebral haematoma (ICH), intraventricular haemorrhage (IVH), aneurysm location with size and number, and timing of surgery. Brain herniation was defined as a deterioration of consciousness accompanied by anisocoria or bilateral pupil dilation (excluding oculomotor nerve palsy caused by other diseases). Rebleeding was defined as neurological deterioration with increase in haemorrhage on CT scan.

\section{Outcome measures}

Functional outcome was assessed by the modified Rankin Scale (mRS). Outcome was dichotomised into good (mRS 0-3) and poor outcome (mRS 4-6). No patients were lost to follow-up. The mean time of follow-up was $12.5 \pm 3.4$ months (range 6-28 months).

\section{Statistical analysis}

An independent-sample $t$ test was used for continuous variables, and a $\chi^{2}$ and Fisher's exact tests were used for categorical variables. Univariate analysis was performed to compare clinical variables between ultra-early and delayed surgery groups. Univariate logistic analysis was performed to determine predictor of poor outcome. Clinical variables with $\mathrm{p}$ value $<0.1$ in univariate analyses were entered into multivariate logistic regression (LR) models. Using the backward LR method, multivariate models were performed to determine factors associated with ultra-early surgery and to identify predictors of poor outcome. Receiver operating characteristic area under the curve (AUC) analysis was used to test the prediction ability. Using the Enter method, the multivariate logistic model was used to assess the effect of ultra-early surgery on outcomes. The adjusted OR and 95\% CI were calculated. Statistical analysis was performed using IBM SPSS V.22.0 (IBM SPSS, Armonk, New York, USA). A $p$ value $<0.05$ was considered statistically significant.

\section{RESULTS}

\section{Patient characteristics}

Of the 144 patients with poor-grade aSAH who underwent surgery, 118 patients were included in the study, and 26 patients were excluded because of neurological deterioration after hospitalisation (from WFNS grades I-III to IV-V) in 23 patients, surgery performed more than 21 days of aSAH in one patient, and last follow-up was less than 6 months in two patients. Demographic and baseline characteristics between ultra-early and delayed surgery groups are shown in table 1 . Forty-seven patients $(40 \%)$ underwent ultra-early surgery, and 
Table 1 Patient characteristics of ultra-early and delayed surgery groups

\begin{tabular}{|c|c|c|c|}
\hline Characteristics & Ultra-early (<24 h) & Delayed (>24 h) & p Value \\
\hline $\mathrm{N}$ (male/female) & $47(21 / 26)$ & $71(29 / 42)$ & 0.680 \\
\hline Age (mean years $\pm S D)$ & $53.9( \pm 12.5)$ & $55.5( \pm 10.8)$ & 0.241 \\
\hline Current smoking, n (\%) & $9(19)$ & $22(31)$ & 0.153 \\
\hline \multicolumn{4}{|l|}{ Medical history } \\
\hline Hypertension, n (\%) & $24(51)$ & $44(62)$ & 0.240 \\
\hline Diabetes mellitus, n (\%) & $6(13)$ & $9(13)$ & 0.989 \\
\hline Postresuscitation WFNS grade, $\mathrm{n}(\%)$ & & & $<0.001$ \\
\hline IV & $19(40)$ & $52(73)$ & \\
\hline $\mathrm{V}$ & $28(60)$ & $19(27)$ & \\
\hline Fisher grade, n (\%) & & & 0.479 \\
\hline $1-1 \mid$ & $4(9)$ & $9(13)$ & \\
\hline III-IV & $43(91)$ & $62(89)$ & \\
\hline Brain herniation, $\mathrm{n}(\%)$ & $23(49)$ & $11(16)$ & $<0.001$ \\
\hline $\mathrm{ICH}, \mathrm{n}(\%)$ & $30(64)$ & $28(40)$ & 0.010 \\
\hline IVH, n (\%) & $16(34)$ & $38(54)$ & 0.038 \\
\hline Multianeurysms, n (\%) & $5(11)$ & $15(21)$ & 0.137 \\
\hline Aneurysm location, n (\%) & & & 0.344 \\
\hline MCA & $24(51)$ & $27(38)$ & \\
\hline ACoA, ACA & $11(23)$ & $24(34)$ & \\
\hline ICA, PCoA & $12(26)$ & $16(23)$ & \\
\hline Posterior circulation & 0 & $3(4)$ & \\
\hline Anterior circulation* & 0 & $1(1)$ & \\
\hline Aneurysm size(mean mm $\pm S D)$ & $6.0( \pm 3.9)$ & $6.3( \pm 3.6)$ & 0.706 \\
\hline Rebleeding before surgery, $n$ (\%) & $1(2)$ & $2(3)$ & 0.966 \\
\hline Improvement before surgery & $2(4)$ & $6(9)$ & 0.474 \\
\hline In-hospital mortality & 7 (15) & $12(14)$ & 0.771 \\
\hline Overall mortality & $15(32)$ & $22(31)$ & 0.915 \\
\hline
\end{tabular}

71 patients $(60 \%)$ underwent delayed surgery. The mean age was $54.9 \pm 11.5$ years (range $19-75$ years). The mean size of aneurysm was $6.0 \pm 4.0 \mathrm{~mm}$ (range $1.0-20 \mathrm{~mm}$ ).

\section{Factors associated with ultra-early surgery}

Patient age, sex, smoking, medical history, aneurysm location and size did not differ between the two groups. Ultra-early surgery was more often performed in patients with WFNS grade V $(\mathrm{p}<0.001)$, brain herniation $(\mathrm{p}<0.001)$, ICH $(\mathrm{p}=0.010)$, without IVH $(\mathrm{p}=0.038$; table 1$)$. After adjustment for WFNS grade, brain herniation, ICH and $\mathrm{IVH}$, multivariate analysis showed that WFNS grade $\mathrm{V}(\mathrm{p}=0.011)$ and brain herniation $(\mathrm{p}=0.004)$ were independent factors for ultra-early surgery compared with delayed surgery (table 2).

\section{Postoperative complications}

Major complications during hospitalisation are presented in table 3. Medical complications, including aneurysm rebleeding, symptomatic vasospasm, cerebral infarction, hydrocephalus and meningitis, and pneumonia, did not differ between the two groups.

\section{Outcomes}

At a mean 12.5 months of follow-up, 58 (49\%) of 118 patients had a good outcome, and overall mortality was observed in $37(31 \%)$. Outcomes in the different timing groups are shown separately in table 4 . Of seven patients for the 13-21 days group, four (57\%) died. Sixteen (34\%) patients in the ultra-early surgery group and 42 $(59 \%)$ patients in the delayed group had good

Table 2 Factors associated with ultra-early surgery compared with delayed surgery

\begin{tabular}{|c|c|c|c|c|}
\hline \multirow[b]{2}{*}{ Predictors } & \multicolumn{2}{|c|}{ Univariate unadjusted } & \multicolumn{2}{|c|}{ Multivariate adjusted* } \\
\hline & OR (95\% Cl) & p Value & OR (95\% Cl) & p Value \\
\hline WFNS grade V & 2.7 (1.3 to 5.8$)$ & 0.010 & 3.0 (1.3 to 7.0$)$ & 0.011 \\
\hline Brain herniation & 5.2 (2.2 to 12.3$)$ & $<0.001$ & 3.8 (1.5 to 9.6$)$ & 0.004 \\
\hline
\end{tabular}


Table 3 Postoperative complications between ultra-early and delayed groups

\begin{tabular}{lccc}
\hline Complications & $\begin{array}{l}\text { Ultra-early } \\
(<\mathbf{2 4} \mathbf{~ h})\end{array}$ & $\begin{array}{l}\text { Delayed } \\
(>\mathbf{2 4} \mathbf{~ h})\end{array}$ & $\mathbf{p ~ V a l u e}$ \\
\hline Aneurysm rebleeding & $2(4)$ & $2(3)$ & 1.000 \\
Symptomatic & $2(4)$ & $8(11)$ & 0.312 \\
vasospasm & & & \\
Cerebral infarction & $9(19)$ & $13(18)$ & 0.909 \\
Hydrocephalus & $4(9)$ & $7(10)$ & 1.000 \\
Meningitis & $3(6)$ & $5(7)$ & 1.000 \\
Pneumonia & $22(47)$ & $28(39)$ & 0.428 \\
\hline
\end{tabular}

outcomes. After adjustment for WFNS grade, brain herniation, ICH and IVH, multivariate analysis showed that the outcomes were similar in the two groups (table 5).

\section{Predictor of poor outcome}

Univariate logistic analysis showed that postresuscitation WFNS grade, Fisher grade, brain herniation, IVH, ultraearly surgery and pneumonia were associated with poor outcome (table 6). Multivariate logistic analysis showed that advanced age $(p=0.010)$, postresuscitation WFNS grade $\mathrm{V}(\mathrm{p}=0.012)$, brain herniation $(\mathrm{p}=0.038)$, IVH $(\mathrm{p}=0.017)$ and non-middle cerebral artery (MCA) aneurysms $(p=0.028)$ were independent predictors of poor outcome (table 7). The multivariate model predicted poor outcome with an AUC of 0.80 (95\% CI 0.72 to $0.88, \mathrm{p}<0.001$; figure 1 ). The timing of surgery was not an independent predictor of poor outcome.

\section{DISCUSSION}

In relatively large, multicentre and contemporary cohorts of poor-grade aSAH, $47(40 \%)$ of 118 patients underwent ultra-early surgery. We determined factors and outcomes associated with ultra-early surgery. Patients with WFNS grade $\mathrm{V}$ and brain herniation more often underwent ultra-early surgery. However, postoperative complications and outcomes were similar between ultra-early and delayed surgery groups. Additionally, we found patents of younger age, postresuscitation WFNS grade $\mathrm{V}$, absence of brain herniation, absence of IVH, and MCA aneurysms were more likely to have a good outcome. Ultra-early surgery was not associated with outcomes in poor grade aSAH.
In the current era where endovascular treatment is often preferred in poor-grade patients, ultra-early surgery was more often performed in patients with ICH, brain herniation and WFNS grade V. Patients with ICH are in severe clinical condition and undergo ultra-early, even emergency surgery. This finding is similar to the previous studies. ${ }^{6} 12 \quad 163132$ Brain herniation is commonly associated with intracranial mass effect caused by ICH. These patients often experience significant brainstem compression. Ultra-early surgery can reduce increased intracranial pressure and increase cerebral perfusion to improve outcomes especially in these patients. Nevertheless, our study showed that the outcomes were similar between the ultra-early and delayed surgery groups. Multivariate analysis also suggested that ultra-early surgery was not a significant predictor of poor outcome. Our results suggested that ultra-early surgery of selected patients with poor-grade aSAH in a tertiary referral centre is safe.

Timing of surgery for good-grade aSAH has shifted from delayed to early surgery over the past decades. The International Cooperative Study on the Timing of Aneurysm Surgery recruited 3521 patients with aSAH. They found no significant differences of good outcomes between early (0-3 days) and delayed (11-14 days) surgery groups. ${ }^{1}$ Siddiq $e t a l^{33}$ reported that early surgery (within $48 \mathrm{~h}$ of admission) was associated with improved outcomes based on the Nationwide Inpatient Sample. Recently, Phillips et $a l^{17}$ analysed an 11-year database of ruptured intracranial aneurysms. Their study showed that ultra-early treatment was associated with improved outcomes in the majority of good-grade aSAH. However, few studies evaluated outcomes in poor-grade aSAH after ultra-early treatment. ${ }^{6} 18{ }^{34}$ Laidlaw and $\mathrm{Siu}^{6}{ }^{34}$ reported that $40 \%$ of patients were independent after 3 months, and that $45 \%$ died. Park et $a l^{18}$ reported that ultra-early surgery did not significantly decrease the incidence of rebleeding of poor-grade aSAH. Ultra-early surgery was also not associated with outcomes. ${ }^{13} 1819$ Our finding is similar to the earlier studies. The possible reason is that the beneficial effect of ultra-early surgery may be impeded by early brain injury after severe aSAH. Nevertheless, our study also showed that complications were frequent in both groups. Major complications including symptomatic vasospasm, cerebral infarction and hydrocephalus did not differ. These observations

Table 4 Outcomes in the different surgical timing groups

\begin{tabular}{lccccc}
\hline Outcomes & Total & Ultra-early $(<\mathbf{2 4} \mathbf{h})$ & $\mathbf{1 - 7}$ days & $\mathbf{8 - 1 2}$ days & $\mathbf{1 3 - 2 1}$ days \\
\hline mRS 0 & $20(17)$ & $5(11)$ & $13(25)$ & $2(17)$ & $1(8)$ \\
mRS 1 & $20(17)$ & $6(13)$ & $13(25)$ & $3(17)$ & 0 \\
mRS 2 & $9(8)$ & $2(4)$ & $3(6)$ & $2(17)$ & $2(29)$ \\
mRS 3 & $9(8)$ & $3(6)$ & $4(6)$ & $3(24)$ & $1(14)$ \\
mRS 4-5 & $23(19)$ & $16(34)$ & $16(31)$ & $2(17)$ & 0 \\
mRS 6 & $37(31)$ & $15(32)$ & & &
\end{tabular}


Table 5 Outcomes associated with ultra-early surgery compared with delayed surgery

\begin{tabular}{|c|c|c|c|c|}
\hline \multirow[b]{2}{*}{ Outcomes } & \multicolumn{2}{|c|}{ Univariate unadjusted } & \multicolumn{2}{|c|}{ Multivariate adjusted* } \\
\hline & OR (95\% Cl) & p Value & OR (95\% Cl) & p Value \\
\hline Outcome (mRS 0-2) & $0.4(0.2$ to 0.8$)$ & 0.014 & 0.5 (0.2 to 1.3$)$ & 0.152 \\
\hline Good (mRS 0-3) & $0.4(0.2$ to 0.8$)$ & 0.008 & $0.5(0.2$ to 1.3$)$ & 0.110 \\
\hline Mortality (mRS 6) & 1.0 (0.5 to 2.3$)$ & 0.915 & 0.7 (0.3 to 1.8$)$ & 0.435 \\
\hline
\end{tabular}

may suggest that with modern neuroanaesthesia, improved neurocritical care and microsurgical techniques, ultra-early surgery is not associated with a higher complication rate than delayed surgery.

Outcomes in poor-grade aSAH have been reported in several studies. $^{26}{ }^{35-37}$ It is still controversial as to which grading (admission grade or postresuscitation grade) is associated with outcomes. $^{13} 24 \quad 36 \quad 38$ We used WFNS grade as initial assessment of aSAH because WFNS grading scale has better interobserver and intraobserver reliability than the Hunt and Hess scale, and makes it more appropriate in different centres. ${ }^{36}$ A large retrospective study showed that admission WFNS grade V was a predictor of discharge outcome. ${ }^{36}$ Other studies reported admission poor grade was not associated with outcomes. $^{16} 3539$ Patients with admission poor grade may probably improve to good grade after hospitalisation. Admission grading is often influenced by patient sedation during referral from outside the hospital. As expected, our study also showed $8(7 \%)$ patients with poor-grade aSAH improved to good grade. We found that postresuscitation WFNS grade was an independent predictor of poor outcome. Our findings suggest that all patients with admission poor grade should be considered for aggressive resuscitations. Clinical condition after resuscitation needs to be evaluated by the multidisciplinary team. Additionally, our study showed that advanced age was associated with poor outcome. This finding is similar to early studies. ${ }^{35-37} 40$ IVH was significantly associated with poor outcome. IVH may probably cause irreversible periventricular brain damage. ${ }^{41}$ Brain herniation at presentation is also associated with poor outcome. We also found that patients with MCA aneurysms were more likely to have a good outcome. This finding may suggest, although endovascular treatment is preferred in poor-grade patients, patients with MCA aneurysms may be considered for surgical treatment.

The primary limitation is that the timing of surgery is not randomised. Many factors, such as delayed referral, logistical factors at the treatment centre, and family

Table 6 Univariate logistic analysis for predictor of poor outcomes

\begin{tabular}{|c|c|c|c|c|}
\hline Characteristics & Good (mRS 0-3) & Poor (mRS 4-6) & OR $(95 \% \mathrm{Cl})$ & p Value \\
\hline $\mathrm{N}$ (male/female) & $58(26 / 32)$ & $60(24 / 36)$ & 0.8 (0.4 to 1.7$)$ & 0.596 \\
\hline Age (mean years $\pm S D$ ) & $52.9( \pm 11.1)$ & $56.8( \pm 11.6)$ & $1.0(0.9$ to 1.1 & 0.063 \\
\hline Current smoking, n (\%) & $18(31)$ & $13(22)$ & $0.6(0.3$ to 1.4$)$ & 0.248 \\
\hline Hypertension, n (\%) & $29(50)$ & $39(65)$ & $1.8(0.9$ to 3.8$)$ & 0.099 \\
\hline Diabetes mellitus, n (\%) & 7 (12) & $8(13)$ & $1.1(0.4$ to 3.3$)$ & 0.894 \\
\hline WFNS grade $\mathrm{V}, \mathrm{n}(\%)$ & $13(22)$ & $34(57)$ & 4.5 (2.0 to 10.1$)$ & $<0.001$ \\
\hline Fisher grades III-IV & $48(83)$ & 57 (95) & 4.0 (1.0 to 15.2$)$ & 0.034 \\
\hline Brain herniation, $\mathrm{n}(\%)$ & $9(16)$ & $25(42)$ & 3.9 (1.6 to 9.3$)$ & 0.002 \\
\hline $\mathrm{ICH}, \mathrm{n}(\%)$ & $26(45)$ & $32(53)$ & $1.4(0.7$ to 2.9$)$ & 0.356 \\
\hline IVH, n (\%) & $21(36)$ & $33(55)$ & 2.2 (1.0 to 4.5$)$ & 0.025 \\
\hline MCA aneurysm, n (\%) & $30(52)$ & $21(35)$ & $0.5(0.2$ to 1.0$)$ & 0.056 \\
\hline Aneurysm size (mean $m m \pm S D$ ) & $6.0( \pm 3.1)$ & $6.2( \pm 4.1)$ & $1.0(0.9$ to 1.1$)$ & 0.775 \\
\hline Rebleeding before surgery, $\mathrm{n}(\%)$ & $1(2)$ & $2(3)$ & $2.1(0.2$ to 24.0$)$ & 0.579 \\
\hline Improvement before surgery & $5(9)$ & $3(5)$ & $0.6(0.1$ to 2.4$)$ & 0.439 \\
\hline Ultra-early surgery & $16(28)$ & $31(52)$ & $2.8(1.3$ to 6.0$)$ & 0.008 \\
\hline \multicolumn{5}{|l|}{ Postoperative complications } \\
\hline Aneurysm rebleeding & 0 & $4(7)$ & - & 0.99 \\
\hline Symptomatic vasospasm & $4(7)$ & $6(10)$ & $1.5(0.4$ to 5.6$)$ & 0.547 \\
\hline Cerebral infarction & $7(12)$ & $15(25)$ & $2.4(0.9$ to 6.5$)$ & 0.077 \\
\hline Hydrocephalus & $4(7)$ & 7 (12) & $1.8(0.5$ to 6.4$)$ & 0.378 \\
\hline Meningitis & $2(3)$ & $6(10)$ & $3.1(0.6$ to 16.1$)$ & 0.176 \\
\hline Pneumonia & $18(31)$ & $32(53)$ & $2.5(1.2$ to 5.4$)$ & 0.015 \\
\hline
\end{tabular}

$\mathrm{ICH}$, intracerebral haematoma; IVH, intraventricular haemorrhage; MCA, middle cerebral artery; WFNS, World Federation of Neurosurgical Societies. 
Table 7 Multivariate logistic analysis of predictors of poor outcome

\begin{tabular}{lll}
\hline Predictors & OR $(95 \%$ CI) & p Value \\
\hline Age & $1.1(1.0$ to 1.1$)$ & 0.010 \\
Resuscitation WFNS grade V & $3.4(1.3$ to 8.7$)$ & 0.012 \\
Brain herniation & $3.3(1.1$ to 10.1$)$ & 0.038 \\
IVH & $3.1(1.2$ to 7.7$)$ & 0.017 \\
Non-MCA aneurysm & $2.7(1.1$ to 6.9$)$ & 0.028 \\
\hline
\end{tabular}

IVH, intraventricular haemorrhage; MCA, middle cerebral artery; WFNS, World Federation of Neurological Societies.

decision-making, may affect the timing of surgery. There is a very wide range of timing of delayed surgery. However, multivariate logical models were performed to adjust for potential confounders between the two groups. Second, this is a selection bias in a multicentre retrospective study. Surgical decision was based on multidisciplinary team consultation. Exclusion of untreated patients and selected patients undergoing surgery might lead to a good outcome. Patients with IVH more often underwent delayed surgery, but current databases cannot identify the definitive reasons. However, these data reflected current surgical practice and outcomes of selected patients with poor-grade aSAH in a tertiary referral centre. Additionally, this study mainly focused on factors and outcomes associated with ultra-early surgical treatment. We did not compare outcomes between surgical and endovascular treatment. Further studies on the comparison of outcomes between two different treatment modalities are warranted to determine the effect of ultra-early treatment of poor-grade aSAH. Nevertheless, this knowledge may help to appraise the

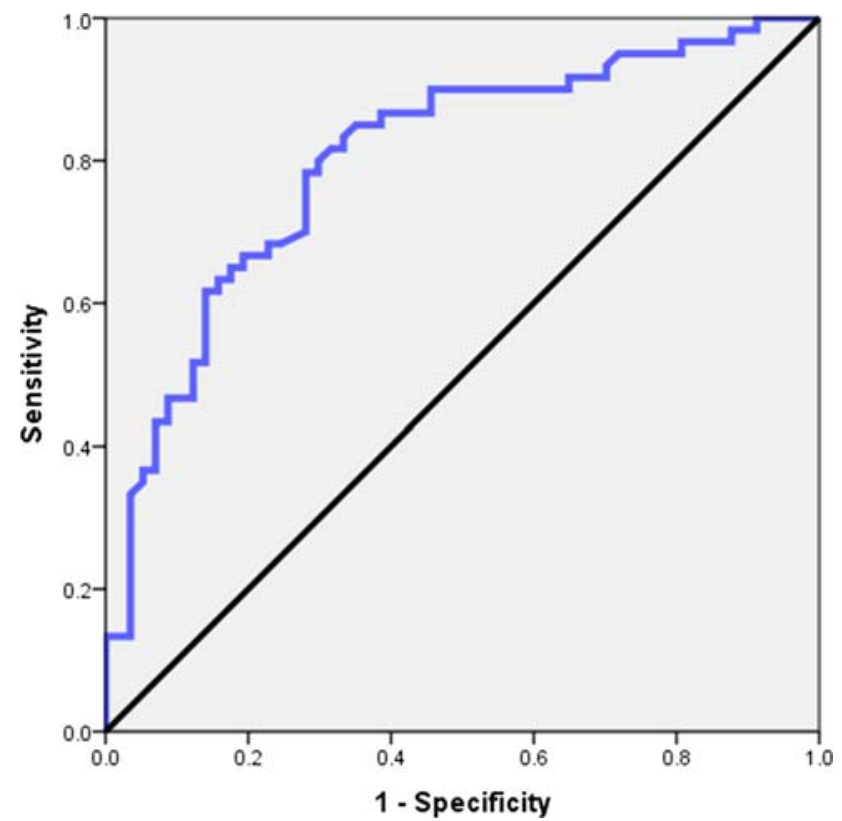

Figure 1 Graph showing the receiver operating characteristic (ROC) curve of predictive value of poor outcome. ultra-early surgery for poor-grade aSAH, and discuss potential outcomes with the family.

\section{CONCLUSIONS}

Although patients with WFNS grade V and brain herniation more often undergo ultra-early surgery, postoperative complication and outcomes in selected patients were similar between the ultra-early and delayed surgery groups. Patients of younger age, WFNS grade IV, absence of intraventricular haemorrhage, absence of brain herniation, and MCA aneurysms are more likely to have a good outcome. Ultra-early surgery could improve outcomes in carefully selected patients with poor-grade aSAH.

\section{Author affiliations}

${ }^{1}$ Department of Neurosurgery, Beijing Tiantan Hospital, Capital Medical University; China National Clinical Research Center for Neurological Diseases (Center of Stroke, Beijing Institute for Brain Disorders, Beijing Key Laboratory of Translational Medicine for Cerebrovascular Disease), Beijing, China ${ }^{2}$ Department of Neurosurgery, First affiliated Hospital of Wenzhou Medical University, Wenzhou, China

${ }^{3}$ Department of Neurosurgery, Mayo Clinic, Rochester, Minnesota, USA

Contributors BZ, YZ, XT, YC, JW, MZ and SW contributed to the study concept and design. BZ and JW contributed to the data collection and analysis. $B Z, M Z$ and $S W$ were involved in interpretation of the data. $B Z$ was involved in drafting of the manuscript. BZ, YZ, XT, YC, JW, MZ and SW contributed to critical revision of the manuscript for important intellectual content.

Funding This work was supported by the National Key Technology Research and Development Program of the Ministry of Science and Technology of China (grant numbers 2013BAI09B03, 2011BAI08B06), National Natural Science Foundation of China (grant number 81471210), Chinese Ministry of Health (grant number WKJ2010-2-016) and Wenzhou Bureau of Science and Technology (grant number Y20090005).

Competing interests None declared.

\section{Patient consent Obtained.}

Ethics approval Chinese Ethics Committee of Registering Clinical Trials; Institutional Review Board of Beijing Tiantan Hospital, Capital Medical University.

Provenance and peer review Not commissioned; externally peer reviewed.

Data sharing statement No additional data are available.

Open Access This is an Open Access article distributed in accordance with the Creative Commons Attribution Non Commercial (CC BY-NC 4.0) license, which permits others to distribute, remix, adapt, build upon this work noncommercially, and license their derivative works on different terms, provided the original work is properly cited and the use is non-commercial. See: http:// creativecommons.org/licenses/by-nc/4.0/

\section{REFERENCES}

1. Kassell NF, Torner JC, Jane JA, et al. The International Cooperative Study on the timing of aneurysm surgery. Part 2: surgical results. J Neurosurg 1990;73:37-47.

2. Roos YB, Beenen LF, Groen RJ, et al. Timing of surgery in patients with aneurysmal subarachnoid haemorrhage: rebleeding is still the major cause of poor outcome in neurosurgical units that aim at early surgery. J Neurol Neurosurg Psychiatry 1997;63:490-3.

3. Fujii Y, Takeuchi S, Sasaki O, et al. Ultra-early rebleeding in spontaneous subarachnoid hemorrhage. J Neurosurg 1996;84:35-42.

4. Fugate JE, Mallory GW, Wijdicks EF. Ultra-early aneurysmal rebleeding and brainstem destruction. Neurocrit Care 2012;17:439-40. 
5. van den Berg R, Foumani M, Schroder RD, et al. Predictors of outcome in World Federation of Neurologic Surgeons grade $\mathrm{V}$ aneurysmal subarachnoid hemorrhage patients. Crit Care Med 2011;39:2722-7.

6. Laidlaw JD, Siu KH. Ultra-early surgery for aneurysmal subarachnoid hemorrhage: outcomes for a consecutive series of 391 patients not selected by grade or age. J Neurosurg 2002;97:250-8; discussion 47-9.

7. Bailes JE, Spetzler RF, Hadley MN, et al. Management morbidity and mortality of poor-grade aneurysm patients. J Neurosurg 1990;72:559-66.

8. Nowak G, Schwachenwald R, Arnold H. Early management in poor grade aneurysm patients. Acta Neurochir (Wien) 1994;126:33-7.

9. Oda S, Shimoda M, Sato O. Early aneurysm surgery and dehydration therapy in patients with severe subarachnoid haemorrhage without ICH. Acta Neurochir (Wien) 1996;138:1050-6.

10. Versari PP, Talamonti G, D'Aliberti G, et al. Surgical treatment of poor-grade aneurysm patients. J Neurosurg Sci 1998;42(1 Suppl 1):43-6.

11. Chiang VL, Claus EB, Awad IA. Toward more rational prediction of outcome in patients with high-grade subarachnoid hemorrhage. Neurosurgery 2000;46:28-35; discussion 35-6.

12. Huang AP, Arora S, Wintermark M, et al. Perfusion computed tomographic imaging and surgical selection with patients after poor-grade aneurysmal subarachnoid hemorrhage. Neurosurgery 2010;67:964-74; discussion 75.

13. Sandstrom N, Yan B, Dowling R, et al. Comparison of microsurgery and endovascular treatment on clinical outcome following poorgrade subarachnoid hemorrhage. J Clin Neurosci 2013;20:1213-18.

14. Le Roux PD, Elliot JP, Newell DW, et al. The incidence of surgical complications is similar in good and poor grade patients undergoing repair of ruptured anterior circulation aneurysms: a retrospective review of 355 patients. Neurosurgery 1996;38:887-93; discussion 93-5.

15. Ungersbock $\mathrm{K}$, Bocher-Schwarz $\mathrm{H}$, Ulrich $\mathrm{P}$, et al. Aneurysm surgery of patients in poor grade condition. Indications and experience. Neurol Res 1994;16:31-4.

16. Hutchinson PJ, Power DM, Tripathi P, et al. Outcome from poor grade aneurysmal subarachnoid haemorrhage-which poor grade subarachnoid haemorrhage patients benefit from aneurysm clipping? Br J Neurosurg 2000;14:105-9.

17. Phillips TJ, Dowling RJ, Yan B, et al. Does treatment of ruptured intracranial aneurysms within 24 hours improve clinical outcome? Stroke 2011;42:1936-45.

18. Park J, Woo H, Kang DH, et al. Formal protocol for emergency treatment of ruptured intracranial aneurysms to reduce in-hospital rebleeding and improve clinical outcomes. $J$ Neurosurg 2015;122:383-91.

19. Wong GK, Boet R, $\mathrm{Ng} \mathrm{SC}$, et al. Ultra-early (within 24 hours) aneurysm treatment after subarachnoid hemorrhage. World Neurosurg 2012;77:311-15.

20. Connolly ES Jr, Rabinstein AA, Carhuapoma JR, et al. Guidelines for the management of aneurysmal subarachnoid hemorrhage: a guideline for healthcare professionals from the American Heart Association/American Stroke Association. Stroke 2012;43:1711-37.

21. Steiner T, Juvela S, Unterberg A, et al. European Stroke Organization guidelines for the management of intracranial aneurysms and subarachnoid haemorrhage. Cerebrovasc Dis 2013;35:93-112.

22. Wostrack M, Sandow N, Vajkoczy P, et al. Subarachnoid haemorrhage WFNS grade $\mathrm{V}$ : is maximal treatment worthwhile? Acta Neurochir (Wien) 2013;155:579-86.

23. Wilson DA, Nakaji P, Albuquerque FC, et al. Time course of recovery following poor-grade $\mathrm{SAH}$ : the incidence of delayed improvement and implications for SAH outcome study design. J Neurosurg 2013;119:606-12.
24. Taylor CJ, Robertson F, Brealey D, et al. Outcome in poor grade subarachnoid hemorrhage patients treated with acute endovascular coiling of aneurysms and aggressive intensive care. Neurocrit Care 2011:14:341-7.

25. Diaz RJ, Wong JH. Clinical outcomes after endovascular coiling in high-grade aneurysmal hemorrhage. Can J Neurol Sci 2011;38:30-5.

26. Pereira AR, Sanchez-Pena P, Biondi A, et al. Predictors of 1-year outcome after coiling for poor-grade subarachnoid aneurysmal hemorrhage. Neurocrit Care 2007;7:18-26.

27. Bracard S, Lebedinsky A, Anxionnat R, et al. Endovascular treatment of Hunt and Hess grade IV and V aneurysms. AJNR Am J Neuroradiol 2002;23:953-7.

28. Suzuki S, Jahan R, Duckwiler GR, et al. Contribution of endovascular therapy to the management of poor-grade aneurysmal subarachnoid hemorrhage: clinical and angiographic outcomes. $J$ Neurosurg 2006;105:664-70.

29. Mitra D, Gregson B, Jayakrishnan V, et al. Treatment of poor-grade subarachnoid hemorrhage trial. AJNR Am J Neuroradiol 2014;36:116-20.

30. Zhao B, Tan X, Yang $\mathrm{H}$, et al. A Multicenter prospective study of poor-grade aneurysmal subarachnoid hemorrhage (AMPAS): observational registry study. BMC Neurol 2014;14:86.

31. Otani $\mathrm{N}$, Takasato $\mathrm{Y}$, Masaoka $\mathrm{H}$, et al. Surgical outcome following decompressive craniectomy for poor-grade aneurysmal subarachnoid hemorrhage in patients with associated massive intracerebral or Sylvian hematomas. Cerebrovasc Dis 2008;26:612-7.

32. Heiskanen O, Poranen A, Kuurne T, et al. Acute surgery for intracerebral haematomas caused by rupture of an intracranial arterial aneurysm. A prospective randomized study. Acta Neurochir (Wien) 1988;90:81-3.

33. Siddiq F, Chaudhry SA, Tummala RP, et al. Factors and outcomes associated with early and delayed aneurysm treatment in subarachnoid hemorrhage patients in the United States. Neurosurgery 2012;71:670-7; discussion 77-8.

34. Laidlaw JD, Siu KH. Poor-grade aneurysmal subarachnoid hemorrhage: outcome after treatment with urgent surgery. Neurosurgery 2003;53:1275-80; discussion 80-2.

35. Le Roux PD, Elliott JP, Newell DW, et al. Predicting outcome in poor-grade patients with subarachnoid hemorrhage: a retrospective review of 159 aggressively managed cases. J Neurosurg 1996;85:39-49.

36. Shirao S, Yoneda $\mathrm{H}$, Kunitsugu I, et al. Preoperative prediction of outcome in 283 poor-grade patients with subarachnoid hemorrhage: a project of the Chugoku-Shikoku Division of the Japan Neurosurgical Society. Cerebrovasc Dis 2010;30:105-13.

37. Mocco J, Ransom ER, Komotar RJ, et al. Preoperative prediction of long-term outcome in poor-grade aneurysmal subarachnoid hemorrhage. Neurosurgery 2006;59:529-38; discussion 29-38.

38. Iosif C, Di Maria F, Sourour N, et al. Is a high initial World Federation of Neurosurgery (WFNS) grade really associated with a poor clinical outcome in elderly patients with ruptured intracranial aneurysms treated with coiling? J Neurointerv Surg 2014;6:286-90.

39. Sasaki T, Sato M, Oinuma M, et al. Management of poor-grade patients with aneurysmal subarachnoid hemorrhage in the acute stage: importance of close monitoring for neurological grade changes. Surg Neurol 2004;62:531-5; discussion 35-7.

40. Shirao S, Yoneda $\mathrm{H}$, Kunitsugu I, et al. Age limit for surgical treatment of poor-grade patients with subarachnoid hemorrhage: a project of the Chugoku-Shikoku division of the Japan neurosurgical society. Surg Neurol Int 2012;3:143.

41. Shimoda M, Oda S, Shibata M, et al. Results of early surgical evacuation of packed intraventricular hemorrhage from aneurysm rupture in patients with poor-grade subarachnoid hemorrhage. J Neurosurg 1999;91:408-14. 